North Kent Railway, on the banks of which the plant is excessively abundant) as to which could record the first blossoms. I think I have seen them as early as the first week in February on the other hand, it is possible that the first week in April is on record as the earliest appearance; almost without exception it truly indicated that any long period of severe weather was over for that winter. Will this prove the case with the socalled "winter" of I $881-1882$ ?

Lewisham, January 6

R. MCLACHLAN

Indian Fossils.-Dr. Gordon, of the Manse, Birnie, Elgin, writes that there is a pretty large collection of Siwalik fossils in the Falconer Museum at Forres, N.B.

\section{THE TRANSIT OF VENUS IN 1882}

THE French Ministry of Public Instruction has issued the Procès-verbaux of the International Conference on the approaching Transit of Venus, held at Paris from the 5 th to the $13^{\text {th }}$ of October last. Representatives of fourteen nationalities were present at the Conference, but regret was expressed that the United States had no delegate present Russia; also was unrepresented, but it has been understood that the Government of that country do not propose to organise expeditions beyond the limits of the Empire, or perhaps to undertake observations elsewhere than at the fixed observatories. M. Jules Ferry, then Minister of Public Instruction and the Fine Arts, was present at the opening meeting of the Conference on October 5 , and stated its objects; he was named honorary president by acclamation, and on his proposition the meeting proceeded to the election of the acting-officers, which resulted in the choice of $M$. Dumas, perpetual secretary of the Academy of Sciences of Paris, as president ; Prof. Fœrster, director of the Observatory of Berlin, and Prof. Weiss, director of the Observatory of Vienna, as vice-presidents; with M. Hirsch, of the Observatory of Neuchâtel, delegate from the Swiss Republic, and M. Tisserand, the proposed chief of a French expedition to Martinique, as secretaries. M. Dumas pointed out that the expeditions in 1874 were organised by the various nations without any general previous understanding, each acting independently, adding that the necessity of cooperation in the arrangements of different countries for the observation of the approaching phenomenon is now generally admitted. He directed special attention to the desirability of coming to some definite conclusion as to the employment or otherwise of photography on the occasion. In the discussion which followed Prof. Fœrster announced that the German Commission had resolved not to employ photography in 1882 , and Mr. E. J. Stone, the Radcliffe Observer, directing astronomer of the British Commission, which he represented at the Conference, mentioned that it was not seriously intended to introduce photography in the expeditions of 1882 , remarking that the French results from this method were not encouraging, and the American results had not been published in time to allow of due discussion before the British Commission was called upon to advise the Government on the best methods of observing the transit.

M. d'Abbadie, however, reminded the Conference that good results had been obtained by $\mathrm{Mr}$. Todd from the American photographs. M. Hirsch said the scientific public had been surprised to find that after the lapse of seven years since the transit of 1874 there was yet but a partial publication of results, and these in small number: each nation had given its solar parallax, but could not a different method of procedure be adopted for the transit of 1882 ? It might be worth while to form a bureau des calculs, charged to collect, reduce, and discuss the whole of the observations in 1882 , and the same bureau might also discuss the entire series of observations at the late transit, and publish the final value of the sun's parallax from the two transits. Prof.,Fœrster took a similar view; Prof. Oudemanns preferred that each commission should in the first place draw up and publish its separate report; the definitive parallax would follow. At the second sitting of the Conference on October $6 \mathrm{M}$. Dumas notified the stations selected by the French Commission and the observers whom it was proposed to place in charge of the respective expeditions. At three of the stations, viz., Santa-Cruz, Rio Negro, and Port-Desire or Chubut, in Patagonia, M. Mansilla from the Argentine Republic, said the French expeditions might count upon the co-operation of his Government, and the same was stated as regards Santiago, another of the French stations, by Dr. Moesta on the part of the Government of Chile. M. Liais, delegate from Brazil, mentioned that M. Cruls would observe at Rio Janeiro, where the sun would be nearly in the zenith soon after the second contact; he had also organised a station in a locality situated at an altitude of 1800 metres to guard against unfavourable weather at Rio, and a third station would be at Pernambuco, where the chances of a clear sky are very great ; further, $M$. Liais contemplated two additional stations, one of them in the Straits of Magellan; the telescopes employed in Brazil would be of 9 inches and 6 inches aperture. Prof. Fœrster stated that the German Government had not finally decided upon the precise localities to which the four authorised expeditions would be sent, but it had been proposed to place two of them in the southern part of the United States, one in the south of the Argentine Republic, and the fourth at the Falkland Islands. With regard to observations in the Straits of Magellan, M. Bouquet de la Grye, of the French Navy, said the Chilian Government had for a long time past instituted meteorological observations which, while they indicated that the probabilities of a fine sky were great at Santiago, were not promising for the Straits: "Il n'y a peut-être pas une probabilité de $1 \tau$ de voir une partie seulement du phénomène." Prof. Fœrster stated that according to his information, there existed near the Magellan Straits very limited localities where the conditions would be favourable in December. With regard to the Antilles, to which expeditions were intended to be sent, the conditions, according to M. Bouquet de la Grye, were complicated: at Martinique they would be pretty good, as also for Florida; at Cuba moderately so ; on the coasts of the Gulf of Mexico the chances of fine weather are small, though improving in the interior. $M$. Pechüle of Copenhagen said the Danish Government proposed, with the assent of the Chambers, to equip an expedition either to St. Croix or St. Thomas. Dr. Bakhuysen said, although the Netherlands Government had not made a final decision, it was proposed to send an expedition to Curacao or St. Martin in the Antilles, and a heliometer would form part of the equipment. M. Viegas, delegate from Portugal, remarking that the weather is usually magnificent in December $n$ that country, mentioned that the observatories of Lisbon and Coimbra possessed large equatorial instruments, and suggested, if it were considered of utility, an expedition might be placed in the Portuguese colonies, at Benguela, for example. Mr. Stone reported upon the selection of stations by the English Commission, the principal centres being the Cape, Australia, New Zealand, and the Antilles. On the part of the Spanish Government, M. Pujazon, director of the Naval Observatory at San Fernando, said it was intended to organise two stations, one at Porto Rico, the other in the southern part of Cuba, where the chances of favourable weather will be considerable: equatorials of 6-inches (English) aperture to be supplied. At the same sitting of the Conference, M. Dumas proposed the nomination of two committees, the one to be charged with the distribution of the observing-stations, the other with the methods and instruments of observation ; it had been previously pointed out by M. d'Abbadie that he was named to conduct an expedition to Cuba on the part of the French Government, where it was now 
stated one would also be sent by Spain : the duplication of stations is not desirable in such a case. The President's propositions were adopted, but in addition the Committee on Methods was also charged with the consideration of the calculations and publication of the observations in 1882 , and were further deputed to consider the formation of a temporary international bureau, to be intrusted with the reduction of the whole of the observations. At the fifth and last sitting of the Conference on October 13, the report from the Committee on Methods of Observation, \&c., was presented. The proposals of the British Commission respecting the phenomena to be noted at the contacts of the limbs of the sun and Venus, brought forward by Mr. Stone, were made the foundation for a series of instructions to observers, some explanations being appended thereto. After much divergence of opinion with regard to the advantage of an international bureau des calculs, the following proposition introduced by M. Dumas, and supported by Mr. Stone on the part of the English commission, was adopted by a large majority.

"The Conference expresses the wish that the French Government may be willing to communicate in diplomatic form with the other governments represented in this conference, or those who are interested in the transits of Venus, in order to lay before them the proposition of convoking, after the return of the expeditions of 1882 , an international conference on the transits of Venus, with a view to establish an understanding on the means to be adopted to arrive at the best and most expeditious use of the observations of the transits of 1874 and 1882 , and in particular to inquire whether towards this end a temporary international bureau should not be formed."

The report closes with a list of the projected stations for the expeditions, so far as at present arrarged. The British stations selected are:-Bermurla, Jamaica, Barbados, Cape Colony (3), Madagascar, New Zealand, Falkland Islands (?), with the Australian observatories.

\section{ON THE PHYSICAL CAUSE OF THE OCEAN}

\section{BASINS}

EOLOGISTS have reason to thank Prof. Ball for directing their attention to the remarkable investigations of Mr. G. H. Darwin upon "The Precession of a Viscous Spheroid, and the Remote History of the Earth," (Phil. Trans. Roy. Soc., Part ii., I879). Prof. Hull has already been led to point out one result which appeared to him to flow from them, in showing how the ancient tides may have produced the planes of marine denudation, though Mr. Darwin has since expressed doubts as to the legitimacy of this conclusion. I wish to offer another speculation arising from Mr. Darwin's work, which I think may account for the hitherto unexplained distribution of land and water upon the surface of the globe.

Herschel remarked long ago, in his "Physical Geography," that the prevalence of land and water over two opposite hemispheres "proves that the force by which the continents are sustained is one of tumefaction, inasmuch as it indicates a situation of the centre of gravity of the total mass of the earth somewhat eccentric relatively to that of the general figure of the external surface - the eccentricity lying in the direction of our antipodes : and is therefore a proof of the comparative lightness of the materials of the terrestrial hemisphere." In my "Physics of the Earth's Crust," just published, I have shown reasons for thinking that the distribution of the materials of the earth, which gives rise to this condition, is of the following kind. I accept on the whole the theory that the earth is a hot globe, of which the superficial crust is rendered solid by having become cool, and that the central part is solid, either from great pressure, or from whatever other cause may be assigned ; an intervening layer beneath the cooled crust still remaining liquid. The layers of which the whole is composed are arranged in order of their density. Now I have given reasons for believing that Herschel's "comparative lightness of the materials of the terrestrial hemisphere" arises from the fact that the cooled crust beneath the continents is intrinsically less dense than that beneath the great oceans. I think that the crust beneath the continents consists of the cooled acid, or granitic, and therefore lighter magma, which ought naturally to have formed originally the entire superficial portion of the globe. But I conclude that the bottoms of the great oceans consist nevertheless of a crust formed out of the cooled basic layer. Beneath the cooled crust the laws of hydrostatic equilibrium would require that, if the substratum is truly liquid, it should be of the same density under both these areas. I also conclude that the upper surface of the basic crust which forms the floor of the oceans is really depressed below the mean surface of figure.

To these conclusions I arrived without being able to suggest any satisfactory explanation of the facts. I saw that they agreed with, and were supported by, the view of those geologists who assert that the great oceanic and continental areas have never changed places; but neither could I any better see the reason for this.

Let us now inquire whether Mr. Darwin's researches throw any light upon the subject. I shall refer chiefly to the summary and discussion of results appended to his paper, for it is small blame to a sexagenarian, not a professed mathematician, to admit that to follow the calculations is beyond the scope of his powers. As I understand Mr. Darwin, he thinks it probable that the moon and the earth were once a single mass, and that at the time when this mass was rotating at the rate of about one revolution in five hours the whole separated into two portions, the smaller of which went to form the moon; and that the moon then began to recede from the earth, until now, after the lapse of fifty-four millions of years or more, it is at its present distance. The ellipticity of the mass when rotating at the above-named speed would be about I-I 2 th. [This would make the mass very much less compressed than an ordinary orange.] He does not think it probable that this amount of ellipticity would cause the spheroid to break up simply from the centrifugal effect of the rotation; but he suggests, judging from the calculated period of a gravitational oscillation of a fluid spheroid, of uniform density equal to the mean of the earth, viz. I hour 34 minutes, that the period of the free oscillation of a spheroid "consisting of a denser nucleus and a rarer surface," but of the same mean density as the earth, might coincide with the period of the bodily solar tide at that time. "It seems to be quite possible that two complete gravitational oscillations of the earth in its primitive state might occupy four or five hours." "Accordingly the solar tides would be of enormous height." He then adds : "Does it not then seem possible that, if the rotation were fast enough to bring the spheroid into anything near the unstable condition, then the large solar tides might rupture the body into two or more parts? In this case one would conjecture that it would not be a ring that would detach itself."

I now proceed to build my speculation upon his. It is obvious that, according to the above theory, the act of fissiparturition by which the moon was born must have been sudden. One of the two solar tidal protuberances broke away from the earth to inchoate a separate existence. A great but shallow hole must consequently have been formed, whose centre would have been on or near the equator. Prof. Ball says : "Not for long would that fragment retain an irregular form; the mutual attraction of the particles would draw the mass together. By the same gentle ministrations the wound on the earth would soon be healed. In the lapse of time the earth would become as whole as ever, and at last it would not retain even a scar to testify to the mighty catastrophe." 